Journalology

\section{International myopia}

\section{B Pless}

\section{Every paper in this journal should have something to offer every reader, no matter where they live}

1 our ongoing efforts to improve this journal, I recently asked the editorial board's advice about several issues. One was to decide what, if anything, we should do with papers that appear to be excessively parochial. These are studies that suffer from what an international journal might view as myopia. No matter how scientifically solid they may be, such papers appear only to be written for colleagues in their own parish. A closely related problem is papers that completely ignore literature on the topic from outside their own country. No sensible investigator can possibly believe that it is only their fellow countryfolk who are doing good work in their field. Such thinking simply adds scientific parochialism to literary parochialism.

Some apparently myopic papers may exist because it is actually the case that the findings only apply to a specific locale. As a rule, these are relegated to brief reports. But more often, it may be that many only seem to be parochial because of how they are written-too little effort is made to capture the interest of those living elsewhere, especially those from other countries. Even large national studies risk being overlooked by readers from other countries if it appears from the title or abstract that the findings only apply to the country of origin. Many readers will ignore papers like this even when they include messages of broad interest and significance.

It is possible, however, that researchers may genuinely believe that findings from Canada have no relevance for the US, for example. Accordingly, consistent with the popular guideline not to speculate beyond what the data can support, these researchers resist commenting on any possible broader implications. In my view they would usually (not always, just usually) be wrong in adopting this strategy but I understand the reasoning behind it.

The fact is that Injury Prevention is truly an international journal. One of the reports I sent to the editorial board prior to this year's World Conference is reproduced in table 1 below. It shows

the countries from which we have received papers over the past two years.

Although just over $50 \%$ of the submissions are from North America, the important fact is that the other half come from nearly 40 other countries! We assume (and hope) our readers reflect this submission pattern. If they do, what is someone from New Zealand, let alone a reader from Sri Lanka, to make of a paper that appears to pertain only to one city in the UK or US? Even if
Table 1 Number of submissions to Injury Prevention by country, 2004-05

\begin{tabular}{|c|c|c|}
\hline Country & $\begin{array}{l}\text { Initial } \\
\text { submissions } \\
\text { (n) }\end{array}$ & $\%$ \\
\hline Australia & 44 & 8.3 \\
\hline Austria & 1 & 0.2 \\
\hline Bangladesh & 2 & 0.4 \\
\hline Brazil & 2 & 0.4 \\
\hline Canada & 56 & 10.5 \\
\hline China & 1 & 0.2 \\
\hline Colombia & 1 & 0.2 \\
\hline Czech Republic & 1 & 0.2 \\
\hline Denmark & 4 & 0.8 \\
\hline Estonia & 1 & 0.2 \\
\hline Finland & 4 & 0.8 \\
\hline France & 1 & 0.2 \\
\hline Greece & 8 & 1.5 \\
\hline India & 11 & 2.1 \\
\hline Iran & 4 & 0.8 \\
\hline Israel & 9 & 1.7 \\
\hline Italy & 4 & 0.8 \\
\hline Jamaica & 1 & 0.2 \\
\hline Japan & 6 & 1.1 \\
\hline Mexico & 5 & 0.9 \\
\hline Netherlands & 5 & 0.9 \\
\hline New Zealand & 17 & 3.2 \\
\hline Nigeria & 4 & 0.8 \\
\hline Norway & 2 & 0.4 \\
\hline Pakistan & 1 & 0.2 \\
\hline Republic of Ireland & 2 & 0.4 \\
\hline Reunion & 1 & 0.2 \\
\hline Singapore & 1 & 0.2 \\
\hline South Africa & 3 & 0.6 \\
\hline Spain & 5 & 0.9 \\
\hline Sri Lanka & 1 & 0.2 \\
\hline Sweden & 15 & 2.8 \\
\hline Switzerland & 3 & 0.6 \\
\hline Syrian Arab Republic & 2 & 0.4 \\
\hline Taiwan & 5 & 0.9 \\
\hline Turkey & 11 & 2.1 \\
\hline Uganda & 0 & 0.0 \\
\hline United Kingdom & 66 & 12.4 \\
\hline United States & 289 & 40.6 \\
\hline Total & 532 & 100.0 \\
\hline
\end{tabular}

a Taiwanese reader was studious enough to plough on, if by the end of the introduction, the same shortsighted perspective prevails, only the most dedicated would read to the end.

In the past, to deal with this issue, we have offered authors of otherwise worthy but narrowly focused papers the option to resubmit them as brief reports. We were, in effect, trying to balance our desire to publish these reports without giving them the same amount of precious space that we provide for original articles of much wider interest. But this solution is far from satisfactory. We now propose that authors ask themselves if readers in other countries would be interested in their report, and if the answer is not evident, we suggest that changes be made to the introduction, discussion, or title (or all three) that would make it more broadly appealing.

This request seems reasonable. One board member pointed out that "For many papers it is not difficult to think about their applicability in an international context. I just think that authors forget to do it. If we specifically asked authors to comment on the wider application of their findings (which may be geographical, cultural, or whatever) this would be helpful." Another board member proposed a set of rules for acceptance, one of which was that any original article should "... be of relevance and interest to a multidisciplinary international audience or a significant part of it, either implicitly or explicitly. That is, a paper should either be of obvious relevance to a wide audience or the authors should explain and/or justify why it is relevant to such an audience."

In effect, the Board agreed that we should press authors to address this problem when it arises. Our decision to do so bumps squarely into one of the ongoing debates about epidemiologic research and is closely related to some persistent disagreement over whether it is appropriate to ask authors to state what their paper's implications for prevention might be. Some hardline epidemiologists are opposed to having authors examine any implications for policy or to speculate on how their data might be used. ${ }^{12}$ At some future date I hope those who hold this view will expound on it.

What we are proposing represents something of a compromise between presuming relevance beyond what is supportable and urging that papers be written so that readers can more easily gauge and interpret their relevance. In our defense and to avoid any misunderstanding, I must make clear that we are not asking authors to specify how their results apply to other countries. Rather 
we are asking them to think carefully about ways in which they can present their work so that its appeal is as broad as possible. Every paper in this journal should have something to offer every reader, no matter where they live. The goal of this exercise is not to cure myopia but to try to limit its negative effects.

Injury Prevention 2006;12:137-138.

doi: 10.1136/ip.2006.012526

Correspondence to: Professor I B Pless, Editor; barry.pless@mcgill.ca

Education

\section{Issues in safety education interventions}

\section{J A Thomson}

\section{The Lifeskills team and their sponsors are to be congratulated for the evaluation reported in this issue}

See linked article on $p 161$

$\mathrm{T}$ he paper by Lamb et al reports an evaluation of a safety education "village" that has been running in Bristol, UK for some years. ${ }^{1}$ The training that children receive is comprehensive and includes safety in the home and garden; on farms and the countryside; by rivers, railways, and building sites. It even addresses product labeling. There is also an element of road safety training, although this is surprisingly limited. In addition to its use with children, the village has been used to help the learning disabled.

To the authors' credit, an evaluation of the program's effectiveness with this population has also been undertaken. The Lifeskills program has a good website (which incidentally contains lengthier reports, both of the current evaluation and of that undertaken with learning disabled adults), and readers interested in the concept of a "safety village" should certainly take the time to visit it (http://www.lifeskills-bristol. org.uk/index.htm).

The concept of a regional training center where children receive intensive exposure to a variety of activities in a single visit is a popular one and has been implemented with varying degrees of sophistication for many years. Such centers have the attraction of providing relatively realistic contexts within which learning can take place and they usually involve at least some degree of practical training which, from a learning point of view, is highly desirable. ${ }^{2}$ Children generally enjoy them and their high face validity makes them popular with both schools and parents.
To some extent this high face validity is their downfall, however-such schemes often appear to be doing so obviously worthwhile a job that evaluation may seem an unnecessary luxury. That, at least, is the conclusion I draw from the relative infrequency with which evaluations are undertaken in this area. In this respect, the Lifeskills team and their sponsors are to be congratulated for the evaluation reported in this issue.

The paper reports very encouraging results which the authors are justified in highlighting. It also raises a number of issues regarding the character of an effective intervention and its evaluation that the reviewers felt deserved a wider airing. Here, I identify some of the issues that were raised in the hope that, by making them explicit, we might assist others considering implementing and evaluating interventions of this type.

The Lifeskills program contains a number of elements that, in principle, represent best practice. An example is the use of group work, in which three or four children cooperate in problem solving under the guidance of an adult volunteer. We ourselves have used this peer collaborative approach extensively in our work on child pedestrian training. ${ }^{3-6}$ However, it is important to emphasize that the benefits of this approach depend entirely on the nature of the interactions that the adult facilitator succeeds in promoting among the children. If trainers interact with the group in much the same way as they would with an individual child,

\section{REFERENCES}

1 Rothman KJ. Policy recommendations in epidemiology research papers. Epidemiology 1993:4:94-5.

2 Weiss NS. Policy emanating from epidemiologic data: what is the proper forum? Epidemiology $2001 ; 12: 373-4$. the approach will offer no particular benefits (other than putting more children through the program in a given period of time). To be effective, the emphasis must be on interaction between the children themselves, with the trainer's role being no more than facilitative.

Conceptual growth occurs (1) as children become aware of points of view conflicting with their own and (2) insofar as joint discussion and activity leads to reconciliation of these points of view within the individual child's cognitive representation. ${ }^{7-9}$ The approach is emphatically non-didactic, with no memorizing of rules or other information, and the measure of success is always the child's ability to construct solutions to new problems rather than repeat previously learned rules or actions. The approach is particularly advantageous where material is complex or conceptually challenging and where there is a danger that children may simply learn to deploy rules or procedures in a rote fashion. As this characterizes so much of children's learning, the peer collaborative approach has found widespread application in many fields. ${ }^{10-16}$

The success of the present intervention-particularly in relation to the long term improvements that are reportedmay well lie in this aspect of the program, although the precise nature of its implementation is far from clear. Nevertheless, this aspect of the intervention deserves to be more widely considered in safety education research.

A second and related issue concerns the relation between knowledge and behavior. Many interventions aim to improve the former on the assumption that improvements in knowledge will generalize to behavior. However, there is little, if any, justification for this assumption. Indeed, measurable improvements in knowledge may give rise to no corresponding changes in behavior at all. ${ }^{217} 18$ To its credit, the Lifeskills program recognizes this and a fair amount of the training focuses on behavior-for example, in physically acting out what to do in the event of a fire. It follows that evaluation should 